\title{
A CASE OF GALACTOSAEMIA WITH SPECIAL REFERENCE TO MENTAL DEVELOPMENT
}

\author{
BY \\ P. R. CLAY and C. T. POTTER \\ From Queen Elizabeth Hospital for Children, London
}

(RECEIVED FOR PUBLCATION OCTOBER 18, 1954)

Galactosaemia was originally described by von Reuss in 1908 and since then a number of cases have been reported. From a study of these a fairly characteristic picture is presented, the most constant features being failure to thrive, hepatomegaly, galactosuria and albuminuria. Other less constant features are mental retardation, jaundice, vomiting, cataract, pyrexia, diarrhoea and a tendency to bleed.

From a description of reported cases the disease appears to vary considerably in its severity. Some patients die in early infancy and, judging from retrospective studies, perhaps some die undiagnosed. Other cases appear to be less severe and may not be diagnosed for several months. One patient reported by Donnell and Lann (1951) was not diagnosed for 13 months though he had had 'nutramigen' for a period. Bray, Isaac and Watkins (1952) report a case diagnosed at 7 years.

With treatment by excluding lactose from the diet many of the clinical features, such as galactosuria and hepatomegaly, disappear and the patients show rapid improvement in physical development. Fox, Fyfe and Mollison (1954) suggest that if therapy is begun early the manifestations of the disease may be reversible, but if delayed, prognosis is poor.

The purpose of this paper is to record the clinical picture and development of a severe case diagnosed in early infancy and kept on a lactose-free diet except for the first month, at which time the diagnosis was presumed, and a period of 14 days when the child was transferred to University College Hospital under Dr. C. E. Dent for confirmation of the diagnosis and for reassessment of his tolerance to galactose. During this latter period the mechanism of amino-aciduria was investigated, and the results of this investigation are presented by Cusworth, Dent and Flynn in the following paper.

\section{Case Report}

M.McK., a boy aged 3 years, was born at full term in September, 1951, weighing $7 \mathrm{lb} .1 \mathrm{oz}$. His mother was physically healthy. The reputed father was stated by the mother to be healthy but he was not interviewed personally by us. The mother had two siblings alive and well and one of her sisters died of heart disease at 17 years. The mother's parents were alive and well at the time of the infant's birth.

The baby appeared well until 7 days old when it was noted that he was not gaining weight and was reluctant with feeds. At 9 days old he was becoming increasingly lethargic and developed jaundice. A small quantity of blood was passed in the stools. The liver and spleen were enlarged and the baby's weight had fallen to $5 \mathrm{lb} .12 \mathrm{oz}$ At this stage septicaemia was suspected and the child was placed on chemotherapy. At 10 days old the baby began to vomit and this persisted until he was admitted to Queen Elizabeth Hospital at 12 days of age.

He was extremely ill, lethargic, and deeply jaundiced. He had a bilateral conjunctivitis and the umbilicus was a little moist. The heart and lungs were normal and there was no obvious abnormality of the central nervous system. The liver was enlarged three fingerbreadths below the right costal margin and the spleen was palpable 1 inch below the left costal margin.

Blood culture was negative. Swabs from the eyes, throat and umbilicus grew Bact. coli. The serum bilirubin level was $26 \mathrm{mg}$. per $100 \mathrm{ml}$, alkaline phosphatase 29 units, thymol turbidity 4 units. The urine showed a cloud of albumin on boiling and there was a complete reduction of Benedict's reagent. No excess of amino-acids in the urine was reported. A glucose tolerance test was normal. The haemoglobin, cell count, and prothrombin, clotting, and bleeding times were all normal.

For the first few days after admission the baby continued to pass streaks of blood in the stools. He remained difficult to feed with intermittent vomiting and no weight gain. The jaundice gradually faded and by the age of 1 month had clinically disappeared. The reducing substance persisted in the urine and the liver and spleen remained enlarged. Galactosaemia was suspected but chemical tests, such as the mucic acid test and the ozazone, were inconclusive. At this stage the eyes were examined by Mr. J. Minton who reported that there was a very small lens opacity in the posterior capsule of the right eye, and a small central lens opacity of the left eye.

At 1 month old when he was $6 \mathrm{lb} .12 \mathrm{oz}$. $(8 \mathrm{oz}$ under 
his birth weight) he was placed on a lactose-free diet as follows:

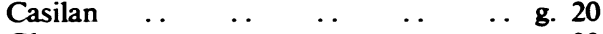

$$
\begin{aligned}
& \begin{array}{lllllll}
\text { Glucose } & \ldots & \ldots & \ldots & \ldots & \ldots & \text { g. } 33
\end{array} \\
& \text { Olive oil .. } \quad \ldots \quad \text { g. } 18 \text { (as emulsion) } \\
& \text { Hartmann's solution } \quad \text {. } \quad \ldots \quad \ldots 5 \mathrm{oz} \text {. } \\
& \text { Salt mixture } \quad . \quad \quad\left(\mathrm{KH}_{2} \mathrm{PO} 6 \cdot 1 \mathrm{~g}\right. \text {., } \\
& \text { mag. sulphate } 4.08 \text { g., ferrous sulph. } \\
& 0.2 \mathrm{~g} \text {., water to } 1,000 \mathrm{ml} \text {.) }=50 \mathrm{c} \text {. } \mathrm{cm} \text {. } \\
& \text { Water to .. } \quad \text {.. } \quad \text {.. } \quad \ldots \quad \ldots 20 \text { oz. }
\end{aligned}
$$

This gave a feed of approximately $3.4 \%$ protein, $5.5 \%$ carbohydrate, and $3 \%$ fat. Later butter, $\frac{3}{4} \mathrm{oz}$, was emulsified as a substitute for olive oil.

Within 48 hours of starting this diet the reducing substance had completely disappeared from the urine. One week later the liver had receded to one fingerbreadth below the right costal margin and the baby was taking feeds well and was gaining weight slowly.

At 14 weeks the baby had a convulsion. There were clonic movements of the face, arms and legs with the wrists held in carpal spasm. Chvostek's sign was negative. He continued to have further mild attacks of twitching which were partially controlled by anticonvulsants, and, although not severe, persisted for about 2 weeks. The convulsions ceased after the baby was placed on mixed feeding. This suggests a possible metabolic cause for the fits. Serum chemistry at this time was persistently normal. From this point the baby progressed slowly apart from intermittent vomiting.

At 5 months old he failed to follow objects with his eyes and made no attempt to grasp objects. At 7 months he was taking an interest in his surroundings but was making no attempt to sit up. At 8 months $\mathrm{Mr}$. Macauley reported that the right lens had a disc-shaped central opacity and the left eye punctate opacities. At 9 months he reported that the left lens opacities had cleared. At $\mathbf{1 0}$ months the baby could hold his head up well and he was able to fix well with his eyes. By 11 months he was able to sit up, and at 14 months he was following objects with his eyes and grasped objects with his hands.

At 21 months a liver biopsy was performed and was reported as being normal by Dr. N. E. France.

At 2 years old the child was walking well round his cot and was laughing and playing but he made no attempt to speak. At this time he was transferred to University College Hospital for the confirmation of the diagnosis and an assessment of the severity of the condition.

At the age of 3 years he weighs $26 \mathrm{lb} .4 \mathrm{oz}$. and his height is $33 \frac{1}{2}$ inches. He is making fair progress physically.

Dr. A. H. Bowley reports as follows on his mental development:

'His speech is very limited, consisting of a few words only. He vocalizes well, vowel and labial sounds especially. He screams when frustrated. He walks well and enjoys exploring, but prefers to crawl or hitch round on his buttocks. As regards his motor coordination, he has difficulty in holding a cup and could not fit round pegs in holes. As regards his adaptive behaviour, he fails to follow instructions to build a block tower, or to replace blocks in a box, or to fit nested boxes together, or to do up loose buttons, or to respond to mirror image verbally. He shows an interest in test materials, handles, sucks, and throws or bangs them to make noise. As regards his social behaviour, he responds to a stranger, accepts friendly advances of older children in the ward, does not appear to know his mother who visits him infrequently, and fails to imitate action suggested by an adult. Bowel and bladder control are not yet achieved. The achievement and skills of this boy are barely equivalent to those of a normal 18-month-old child, and his effective intelligence at present appears only that of a feeble-minded child.'

\section{Discussion}

The diagnosis of galactosaemia in this case was presumed at 1 month old from the clinical picture, namely lethargy, failure to thrive, vomiting, jaundice, hepatomegaly, cataract, and a reducing substance in the urine which disappeared on a lactosefree diet.

It has been suggested that if treatment is instituted early the manifestations of the disease are largely reversible. This appears to be so as regards the hepatomegaly and cataract, but it is doubtful if the mental retardation responds in the same way or if it depends on the same factors. The occurrence of mental defect is the most serious manifestation of the disease and it is important to determine whether it is an integral part of the syndrome or a complication of the metabolic disorder. From the literature it is difficult to assess the exact mental state of many of the cases reported.

Goldbloom and Brickman (1946) reported two cases, one of which showed no mental retardation, and they quoted a case of Norman and Fashena (1943) where the mentality was normal. In these cases treatment was started early, at $3 \frac{1}{2}$ months and 11 weeks respectively. They suggested that the mental retardation was not an associated congenital defect but the result of interference by the galactosaemia with the supply of glucose to the brain tissue or a direct toxic effect of galactose.

On the other hand a case reported by Townsend, Mason and Strong (1951) was treated within a few days of birth and remains mentally retarded. As already stated the case reported in this paper was on a lactose-free diet from 1 month old (apart from a period of 14 days at 2 years old for re-assessment) and yet is severely mentally deficient. It is admitted that the lactose-free diet contained 'casilan' and we note that Komrower and Holzel in a letter to the British Medical Journal of October 2, 1954, state that the small quantity of lactose in 'casilan' is excessive for such infants. They draw attention to three 
infants treated early with 'correct dietary measures' where the mental and physical development was normal. It is not stated at what age the mental assessment was made or the pattern of social behaviour they exhibited.

In the case reported here there are various possibilities for the mental retardation.

Parental Background. The father's mentality is unknown. The mother has not been definitely assessed, but judging from correspondence from her her scholastic attainments are poor. Socially she is a pleasant and amiable person, going out to work and earning her own living. She is concerned about the child's welfare and shows appreciation of the efforts made on his behalf. She appears to be in the 'dullard' group, just below the limit of average intelligence.

Convulsions. The child suffered from convulsions at $3 \frac{1}{2}$ months old, and it is possible that these may have been a factor in his mental retardation. However, the convulsions were never severe and have not recurred.

Effect of Hospital. The child has been in hospital since birth and has therefore lacked the benefit of the stimulation he might have received in a good home. On the other hand he has had more attention from sisters, nurses and doctors than the average hospital patient, and we consider his degree of retardation too great to be attributed to deprivation of adequate stimulus alone.

Effect of the Disease Itself. Mason and Turner (1935) found that a high blood galactose depressed the blood glucose and suggested that the derangement in tissues other than the liver might be due to the continuous hypoglycaemia. One case reported by Townsend, Mason and Strong (1951) had hypoglycaemic shock after ingestion of galactose. Bruck and Rapoport (1945) criticize the hypoglycaemic hypothesis and point out that hypoglycaemia per se (for example, in glycogen storage disease and hyperinsulinism) does not produce similar symptoms.

If a toxic effect of galactose or a resulting hypoglycaemia were the direct cause of the mental defect the action would appear to be very selective as there is no evidence of permanent damage to other parts of the central nervous system.

Although the weight of evidence so far supports the view that the mental defect is of a secondary nature, a study of many more cases is needed before the possibility of a genetic origin of the retardation independent of the metabolic disorder can be ruled out. In subsequent studies of the condition, especially in those diagnosed and treated early on a diet completely free from lactose, we would urge a close study of the mental development, not only as regards an intelligence quotient, but also with a view to assessing the temperamental, adaptive and social behaviour.

We would like to record our thanks to Dr. C. E. Dent for his valuable help, and to Dr. A. H. Bowley for her assessment of the patient's intelligence.

\section{ReFERENCES}

Bray, P. T. Isaac, R. J. and Watkins, A. G. (1952). Archives of Disease in Childhood, 27, 341.

Bruck, E and Rapoport, S. (1945). Amer. J. Dis. Child., 70, 267

Donnell, G. N. and Lann, S. H. (1951). Pediatrics, 7, 503.

Fox, E. G., Fyfe, W. M. and Mollison, A. W. (1954).' Brit. med. J., 1, 245 .

Goldbloom, A. and Brickman, H. F. (1946). J. Pediat., 28, 676 Mason, H. H. and Turner, M. E. (1935). Amer. J. Dis. Child., $50,359$.

Norman, F. A. and Fashena, G. J. (1943). Ibid., 66, 531

Reuss, A. von (1908). Wien. med. Wschr., 58, 799. Townsend, E. H., Mason, H. H. and Strong, P. S. (1951). Pediatrics,
7, 760 . 